\title{
The Value Creation of Social Media Information
}

\author{
Tajinder Kaur Bahia ${ }^{1}$ and Antonis Constantinou Simintiras ${ }^{2}$ \\ ${ }^{1}$ Marketing In New Times (MINT) Research, Warwick, UK \\ \{tajinderkbahia@gmail.com $\}$ \\ ${ }^{2}$ Gulf University for Science and Technology, College of Business Administration, Kuwait \\ \{Simintiras.A@gust.edu.kw\} \\ Swansea University, School of Management, Swansea, South Wales, UK
}

\{a.c.simintiras@swansea.ac.uk\}

\begin{abstract}
Abstract. Social media information is a useful barometer of value characterising the digital age. To identify the core contributors of value creation, value is in the 'eye of the beholder', and 'sharing' social media information is indicative of communicating such perceived value. Sharing allows for belongingness, as people do not simply connect with communities, they contribute to communities, and shape them too. Content that is shared needs to be credible, especially as the power to persuade is being co-created by consumers. This is facilitated by sharing content deemed truthful and relevant; accordingly, information conveyed needs to be accurate and timely. Drawing from social network theory and Buckner's (1965) theory on rumour transmission, we argue that the value of social media information is significantly created from an interplay of: (i) 'sharing', (ii) 'persuasion' and (iii) 'timing'. This interplay is not exhaustive, however, as other contributors may exist, thus further research is advocated.
\end{abstract}

Keywords: social media information $\cdot$ value creation $\cdot$ sharing $\cdot$ persuasion $\cdot$ timing $\cdot$ belonging $\cdot$ accuracy $\cdot$ speed

\section{$1 \quad$ Introduction}

This paper appraises the finer intricacies of value creation in the ever popular and fast-paced domain of social media. Social media may be defined as an array of Internet-based applications that develops and builds up from the conceptual ideology and high-tech fundamentals of Web 2.0, allowing for the formation and interchange of user-generated content (UGC) [1,2]. This conceptualisation suggests that Web content is not simply consumed by users in a passive sense. Instead, it is created, shared and consumed by people who are actively generating content [1]. Indeed, a number of different research efforts exist that focus on the significance of UGC across differing contexts. Although there exist a many number of varied platforms for social media to include social networking, text messaging, photo sharing, wikis, weblogs, and discussion forums, it is mostly shaped by the more prevalent Internet-based applications to include 'YouTube', 'Facebook', 'Second Life', 'Wikipedia', and 'Twitter' [1,2].

When appraising the motivations for sharing experiences via social media, sharing practices emerge as valuable constructions of sociability and emotional support [3]. Social media is also understood as the digital version of word-of-mouth communication [4], as each and every individual is able to connect with many hundreds, if not thousands of other like-minded individuals on matters relating to the services and products, as well as the organisations that offer them [5]. Each and every individual is indispensable to the creation of value, and with the advent of 'influence marketing', this kind of marketing centres on main personalities and 
characters, rather than on a target market [5]. Accordingly, there seems to have been significantly more burden placed on organisations to source out key Social Media Influencers (SMIs) [6,7], as a firm's collaboration with its customers may potentially result in entire marketing programs being co-created $[8,9]$.

In terms of marketing, social media is a hybrid constituent of the promotion mix considering that in the traditional sense it allows businesses to communicate with their customer base, yet also in the not so traditional sense, it allows customers to communicate openly and directly with one another [5]. Drawing insights from consumer culture theory, collectives deliver value to members via progressive sharing activities of numerous styles, thus consumer-based collectives constitute the basis of considerable value creation [9]. Arguably, as the information value constituents' shift, so too does the focus of marketing messages shift. Notwithstanding, the sharing of information and consumer experiences by brand communities on social media are found to be key to marketers' efforts to form relations with customers [2], [10,11], which can serve to fulfil a person's need for belongingness [2], [12], and identity [9].

\section{The Core Contributors of Value Creation for Social Media}

As the bearing of consumer-to-consumer communications has become significantly exaggerated in the ever-virtual marketplace [5], to guide our research efforts that elucidate upon the core contributors of value creation for social media, established theoretical paradigms for examining and explaining how people develop networks, voice opinions, and share information include social network theory [4], [13], social exchange theory [4], [7], and social penetration theory [4]. Also of significance, the theory of rumour transmission (theory of communication) indicates the speed and accuracy of a rumour passing are affected by the structure of the network and the mind-sets (namely, critical ability) of the individuals in the network [4], [14]. Accordingly, people's interest and involvement serve to shape the content, timing, and frequency of information transmission [14].

As social media exchanges are beyond management's direct control [9], they are compelled to respond with credibility that is well-timed [15]. Similarly, sharing (and liking) social media can augment the effects of 'popular cohesion' and 'message diffusion' [16]. In particular, they explore how persuasive messages to encompass the notion of 'argument quality', can induce people to share and like messages. On a par with their research, we advocate that 'accuracy' ultimately underpins persuasive social media content that people want to share and relate to, with 'timing', explicitly 'speed' of response (comparable to that of message diffusion) being essential for firms seeking to cultivate the value creation process of social media information. Content that is shared calls for credibility, and as the power to persuade now also resides with the consumer, this can be facilitated by sharing content that is deemed persuasive, truthful and relevant (that is, accurate and timely). With this in mind, we argue that the value of social media information is significantly created from an interplay of: (i) 'sharing', (ii) 'persuasion' and (iii) 'timing'. These constituents are discussed in greater detail below.

\subsection{Sharing - Belongingness and Identity}

The sharing of social media information, also referred to as 'consumer-generated media', allows for a sense of belongingness [2], [12], as people do not simply connect with communities, they contribute to, as well as shape them too [17]. Three core attributes are deemed important for marketers to consider when persuasion is employed to engage as sense 
of ownership that leads to the sharing social media information [6]. These are: (i) relevance, (ii) reach, and (iii) resonance. Relevance pertains to the actual content influencers are sharing deemed relevant to a business [6] by creating and negotiating meaning [2]. Reach refers to the number of people one could hypothetically influence in accord with an influencer's follower base, thus bringing value to a business [6] [17]. Resonance is understood as feeling engaged and identifying with an audience from sharing content that is relevant [6]. Hitherto, creating reflections of an extended digital self is facilitated by the practice of sharing content $[18,19]$. Responses by others and retweets add value to a person's collection of social media information [19].

What is more, by creating social presence the awareness of connectedness and the feel of being in touch with others can endure as an experience deemed to be extremely engaging [1], [20]. To tap this aspect of human communication, a 'Connectedness Questionnaire' has been developed that focuses upon the affective advantages of the awareness systems [20]. Hypothesised affective gains span the feeling of companionship, a resilient group pull, a feeling of remaining in touch, of staying informed with other people's lives, as well as a sense of sharing, belonging, and closeness [20]. In a nutshell, awareness systems are not perceived as substituting prevailing communication means, but more so as a way to enhance them, to fortify social bonds, and enable new varieties of interaction [20].

\subsection{Persuasion - A Need for Accuracy}

Leading SMIs espouse and voice opinions that other people listen to, and are persuaded by [7]. It is important to see what this means for business [6]. By engaging with SMIs an organisation is able to intensify levels of awareness underpinning its brand, as well as build brand advocates, augment online reputation, and escalate page rank. Thus, whether the objective of one's business is to augment awareness or to increase SEO (search engine optimisation) traffic, SMIs constitute a viable source of business support [6] and contribute to effective communication strategies [7].

In certain instances, word of mouth updates are deemed as extremely persuasive, and are even professed as more dependable and truthful than more mainstream broadcasting mediums [21]. In a recent survey more than $90 \%$ of the communication practitioners surveyed were confident that blogs and social media now influence mainstream news [21]. Social media is considered by consumers as being a more trustworthy source of information regarding products and services than corporate-sponsored communications transmitted via the traditional elements of the promotion mix [5], [22]. Reputation becomes a key factor. For instance, when appraising the SMI, a person's reputation online is found to factor in the strength and credibility of social media influence. Thus, the more persuasive and influential an individual is, the better the reputation of the individual [6].

SMIs facilitate marketing agendas via the practice of creating relationships. Even if an influencer's audience is niche or mass, an influencer can go about reaching a target group of consumers via their blogs and social networks that a brand in and of itself may not be able to influence [6]. Truth and accuracy are the building blocks of such relationships. Experts, for example, are always advised to be truthful and endeavour for accuracy, as truth and accuracy are basic principles, which ought to be endorsed as far as is feasibly possible [23]. Still, that is not to say there are many experts [24]. Transparency and accountability are called for to function efficiently, with impunity, particularly in a setting where people are actively immersed in online conversations [25]. Consumers are also more refined, visibly dubious and extremely demanding. The speed with which such changes are directly impacting marketing 
communication is remarkable [17], and indisputably necessitates a redrafting of the rules for handling matters such as reputation and brand management [25]. With this in mind, and tying in with the discussion on 'timing' to follow, we advocate the influencer's speed of response plays a significant part in shaping reputation.

\subsection{Timing - Speed is of the Essence}

Unlike any other platform of communications, including TV and radio, social media reach has proved to be the speediest in terms of reach and influence [17]. YouTubers upload in excess of 100 hours of video each and every minute on a daily basis. That is approximately equal to 500,000 full length movies uploaded per week. More video is broadcast on YouTube in a month, compared with the last 60 years on broadcasting networks such as ABC, NBC, and CBS combined [17]. Time, in terms of speed and reach, is certainly of the essence when engaging with the throes of social media. Arguably therefore when it comes to mastering the domain of social media, survival of the fittest today may be better framed as 'survival of the fastest' [26]. Investments in new communication and information technologies serve to transcend geographic boundaries [5], to greatly alter traditional conceptualisations and perceptions of space, time, and interaction, and especially due to how efficiently, if not speedily, such technologies are facilitated [27,28,29,30].

In light of today's changing conceptualisations of time and space as a result of advancing technology, the speed of transactions and the transference of information have elevated to heights of incomparable importance [1], [31,32,33,34]. Indeed, when appraising the significance of speed, over recent years global communication has advanced at an unprecedented speed [28,29,30], [34]. As each day passes the sway of social media magnifies as more and more people become a part of new online communities [1], [17]. As an illustration, Facebook is a social utility that offers synchronous relations, which take place in real time, as when people text back and forth with friends, as well as asynchronous relations, which do not necessitate replies are made instantaneously, as when sending an email to a friend and a reply is received the following day. Also on offer with Facebook are opportunities for content sharing of pictures, music/ audio, video footage, games, apps, groups, spanning in excess of 1.2 billion active users [17].

Potentially therefore, it may be that the speed of response can be construed as a measure of relational strength imbibed with a particular sense of significance. Undeniably, the power of web-based networks has amplified the speediness, scope of influence and interactivity of social media information and communication [1], [25]. In the present age of the social web, disclosed informal boardroom discussions can appear on the Internet in a matter of seconds, and records leaked through mass mail can be published and commented upon in blogs within a few minutes [25]. Invariably, the speed of such undertakings can potentially impair the image of a company and generate opinions of corporate negligence and a lack of responsibility [25]. Hence, timely action imbibed with speed is called for.

\section{Conclusions and Directions for Future Research}

The present paper has argued that the value of social media information is created from an interplay of sharing, persuasion, and timing. As it is accepted that this interplay is not exhaustive (as other contributors may exist), further research efforts by academics and marketers are encouraged. Accuracy of social media information is argued to give way to 
persuasion. Future research may seek to explore this relationship in terms of brand involvement/ engagement/ loyalty, honing in on the marketing efforts of SMIs specifically. As loyalty and engagement are significant to the value creation of social media information, future research may seek to explore if this is actually more apparent by regular and timely acts of sharing credible content with significant others that render a collective sense of belonging (identity).

Future research may seek to explore the darker side of value creation of social media information. That is, in terms of the value creation of social media information, anyone, anywhere with access to technology can share such information to feel belongingness and carve out an identity, yet the darker side of this chain is that if the means to engage and persuade in the domain of social media was taken away from people, would all types of social networks (to include digital natives and SMIs) habitually feel lost, alone, and at a loss for what to do [17]?

\section{$4 \quad$ References}

1. Kaplan, A.M., Haenlein, M.: Users of the world, unite! The challenges and opportunities of social media. Bus. Horizons, 53, 59-68 (2010)

2. Laroche, M., Habibi, M.R., Richard, M.O.: To be or not to be in social media: How brand loyalty is affected by social media? Int. J. Inform. Manage. 33, 76-82 (2013)

3. Munar, A.M., Jacobsen, J.K.S.: Motivations for sharing tourism experiences through social media. Tourism Manage. 43, 46-54 (2014)

4. Pan, B., Crotts, J.: Theoretical models of social media, marketing implications, and future research directions. In: Sigala, M., Christou, E., Gretzel, U. (eds.). Social Media in Travel, Tourism and Hospitality: Theory, Practice and Cases, pp. 73-86. Ashgate, Surrey (2012)

5. Mangold, W.G., Faulds, D.J.: Social media: The new hybrid element of the promotion mix. Bus. Horizons, 52, 357-365 (2009)

6. Cisnero, K.: To Engage And Create A Lasting Relationship With Social Media Influencers, https://blog.hootsuite.com/how-to-find-social-media-influencers

7. Ngai, E.W., Tao, S.S., Moon, K.K.: Social media research: Theories, constructs, and conceptual frameworks. Int. J. Inform. Manage. 35, 33-44 (2015)

8. Lusch, R.F., Vargo, S.L.: Service-Dominant Logic as a Foundation for Building a General Theory. In: Lusch, R.F., Vargo, S.L. (eds.) The Service-Dominant Logic of Marketing, pp. 406-420. M.E. Sharpe, Armonk, NY (2006)

9. Schau, H.J., Muñiz Jr, A.M., Arnould, E.J.: How brand community practices create value. J. Marketing. 73, 30-51 (2009)

10. De Vries, L., Gensler, S., Leeflang, P.S.: Popularity of brand posts on brand fan pages: An investigation of the effects of social media marketing. J. of Interact. Mark. 26, 83-91 (2012)

11. McAlexander, J.H., Schouten, W.J., Koening, F.H.: Building brand community. J. Marketing, 66, 38-54 (2002)

12. Gangadharbatla, H.: Facebook me: Collective self-esteem, need to belong, and internet selfefficacy as predictors of the iGeneration's attitudes toward social networking sites. J. Interact. Advert. 8, 5-15 (2008)

13. del Fresno García, M., Daly, A.J., Segado Sánchez-Cabezudo, S.: Identifying the new Influences in the Internet Era: Social Media and Social Network Analysis. Rev. Esp. Invest. Sociol. 153, 23-40 (2016)

14. Buckner, H. T.: A theory of rumor transmission. Public Opin. Quart. 29, 54-70 (1965) 
15. Moreno, A., Navarro, C., Tench, R., Zerfass, A.: Does social media usage matter? An analysis of online practices and digital media perceptions of communication practitioners in Europe. Public Relat. Rev. 41, 242-253 (2015)

16. Chang, Y.T., Yu, H., Lu, H.P.: Persuasive messages, popularity cohesion, and message diffusion in social media marketing. J. Bus. Res. 68, 777-782 (2015)

17. Tuten, T.L., Solomon, M.R.: Social media marketing. Sage, London (2014)

18. Carroll, E., Romano, J.: Your digital afterlife: When Facebook, Flickr and Twitter are your estate, what's your legacy? New Riders, Berkeley, CA (2011)

19. Belk, R.W.: Extended self in a digital world. J. Consum. Res. 40, 477-500 (2013)

20. IJsselsteijn, W., van Baren, J., van Lanen, F.: Staying in touch: Social presence and connectedness through synchronous and asynchronous communication media. In: Stephanidis, C., Jacko, J. (eds.) Human-Computer Interaction: Theory and Practice (Part II), vol. 2 of the Proceedings of HCI International, pp. 924-928. Lawrence Erlbaum, Hillsdale, NJ (2003)

21. Veil, S.R., Buehner, T., Palenchar, M.J.: A work-in-process literature review: Incorporating social media in risk and crisis communication. J. Conting. Crisis Manag. 19, 110-122 (2011)

22. Foux, G.: Consumer-generated media: Get your customers involved. Brand Strat. 8, 3839 (2006)

23. Murphy, D.G., Loeb, S., Basto, M.Y., Challacombe, B., Trinh, Q.D., Leveridge, M., Morgan, T., Dasgupta, P., Bultitude, M.: Engaging responsibly with social media: the BJUI guidelines. BJU Int. 114, 9-11 (2014)

24. Solis, B., Breakenridge, D.K.: Putting the public back in public relations: How social media is reinventing the aging business of PR. FT Press, Upper Saddle River, NJ (2009)

25. Jones, B., Temperley, J., Lima, A.: Corporate reputation in the era of Web 2.0: the case of Primark. J. Marketing Manage. 25, 927-939 (2009)

26. Greengard, S.: The Need for Speed. Workforce, 79, 20-21 (2000)

27. Harvey, D.: The Condition of Postmodernity. Blackwell, Oxford (1989)

28. Kaufman-Scarborough, C.: Time Use and the Impact of Technology: Examining workspaces in the home. Time Soc. 15, 57-80 (2006)

29. Turner, J.W., Grube, J.A., Tinsley, C.H., Lee, C. O'Pell, C.: Exploring The Dominant Media: How Does Media Use Reflect Organizational Norms and Affect Performance? J. Bus. Commun. 43, 220-250 (2006)

30. Turner, J.W., Reinsch, N.L.: The Business Communicator as Presence Allocator: Multicommunicating, Equivocality, and Status at Work. J. Bus. Commun. 44, 36-58. (2007)

31. D'Aveni, R.A., Gunther, R.: Hypercompetition: Managing the Dynamics of Strategic Maneuvering. The Free Press, New York (1994)

32. Fine, C.H.: Clockspeed: Winning industry control in the age of temporary advantage. Perseus, New York (1998)

33. Rubin, D.: Velocity management rush. IIE Solut. 33, 36-39 (2001)

34. Bianchi, C., Mathews, S.: Internet marketing and export market growth in Chile. J. Bus, Res. 69, 426-434 (2015) 